\title{
José Medina Echavarría y su contribución a la reflexión teórico- conceptual en Latinoamérica
}

\author{
Laura Angélica Moya López ${ }^{1}$
}

Fecha de recepción: 1 de julio de 2017

Fecha de aprobación: 21 de agosto de 2017

\begin{abstract}
Resumen
José Medina Echavarría es reconocido como uno de los sociólogos más destacados del exilio español en Latinoamérica. Hoy, al conmemorarse el XL aniversario de su muerte, cobra actualidad la lectura de su obra en temas como la reflexión teórica y la producción conceptual. En la región se debate constantemente sobre los procesos de recepción de las tradiciones sociológicas densas y la necesidad de enunciar y conceptuar sobre fenómenos históricos o procesos novedosos o inéditos. En esta tensión entre acumulación de tradiciones y la producción teórica como lenguaje de segundo orden, Medina aportó reflexiones seminales y de inspiración weberiana para el análisis sociológico contemporáneo, destacando, entre ellas, la diferenciación entre teorías verticales y horizontales, la sociología analítica y estructural, y las tensiones entre investigación empírica y producción teórica.
\end{abstract}

Palabras clave: sociología latinoamericana, José Medina Echavarría, teoría sociológica, Max Weber.

\section{José Medina Echavarría and his contribution to the conceptual theoretical reflection in Latin America}

\begin{abstract}
José Medina Echavarría is recognized as one of the most outstanding sociologists of Spanish exile in Latin America. Today, at 40 years from his death, it becomes relevant to read his work on topics such as theoretical reflection and conceptual production. There is a constant regional debate about the processes of reception of dense sociological traditions and the need to state and conceptualize historical phenomena or novel or unpublished processes. In this tension between accumulation of traditions and theoretical production as a second-order language, Medina provided seminal and Weberian-inspired insights for the contemporary sociological
\end{abstract}

1 Dra. en Historia, UNAM. Profesora Investigadora de Tiempo Completo, Departamento de Sociología, Universidad Autónoma Metropolitana, Unidad Azcapotzalco, Ciudad de México. Contacto: laml10@yahoo.com 
analysis, highlighting, among them, the differentiation between vertical and horizontal theories, analytic and structural sociology, and tensions between empirical research and theoretical production.

Keywords: Latin American sociology, José Medina Echavarría, sociological theory, Max Weber.

\title{
José Medina Echavarría e sua contribuição para a reflexão teórica conceitual na América Latina
}

\begin{abstract}
Resumo
José Medina Echavarría é reconhecido como um dos sociólogos mais destacados do exílio espanhol na América Latina. Hoje, ao se comemorar o XL aniversário de sua morte, torna-se atualidade, a leitura de sua obra em temáticas como a reflexão teórica e a produção conceitual. Na região há um debate constante sobre os processos de recepção das tradições sociológicas densas e a necessidade de indicar e conceituar fenômenos históricos ou processos novos ou inéditos. Nessa tensão entre acumulação de tradições e a produção teórica como linguagem de segunda ordem, Medina forneceu ideias seminais e de inspiração weberiana para análises sociológico contemporâneo, destacando entre elas a diferenciação entre teorias verticais e horizontais, a sociologia analítica e estrutural, e as tensões entre pesquisa empírica e produção teórica.
\end{abstract}

Palavras-chave: sociología latino-americana, José Medina Echavarría, teoria sociológica, Max Weber.

\section{Introducción}

La conmemoración del cuarenta aniversario de la muerte de José Medina Echavarría es una ocasión inmejorable para reflexionar acerca de por qué el legado de un autor puede convertirse en un ejercicio para reconocer que la sociología se desarrolla en un arco de tensión entre acumulación de teorías, metodología y tradiciones de investigación, y la innovación en estos mismos ámbitos. Entre esos extremos, las comunidades intelectuales se reconocen o no en los legados de los antecesores, en cadenas intergeneracionales de recuerdos que pueden verse interrumpidas, fragmentadas o permanecen desconocidas para las nuevas generaciones, ávidas de novedades y en el marco de una experiencia del pasado que se ha acortado. Los ciclos conmemorativos son procesos rituales que contribuyen a la formación de recuerdos sociales compartidos, en este caso en torno a un autor y su obra, a 
la luz de los cuales interpretamos el presente. Conmemorar a Medina implica representar un logro acumulativo y un patrimonio de conocimiento - en este caso, en el ámbito de la sociología latinoamericana- que amerita una nueva lectura de sus reflexiones, a la luz de uno de los temas que se plantean de manera reiterada en la agenda regional: la importancia de la producción teórica y la reflexión conceptual.

Recordar a José Medina Echavarría (Castellón de la Plana, Valencia, 1903 - Santiago de Chile, 1977)² significa recolocar en el presente a un antecesor que, en el marco del diagnóstico sobre la crisis de la cultura occidental moderna y frente a las experiencias de la guerra, el desarraigo y la desorientación vital producto del exilio, logró elaborar reflexiones muy acabadas sobre cómo era factible la comprensión, asimilación y re-significación de la experiencia vivida a partir de la perspectiva sociológica y la reelaboración conceptual. Es importante señalar que las contribuciones de Medina a la sociología latinoamericana se produjeron en un contexto fundacional de la institucionalización de las ciencias sociales en la región. Recordemos que el proyecto desarrollista para América Latina y otras regiones requería de la formación de profesionales capaces de diagnosticar y diseñar políticas públicas, para corregir aquellos factores estructurales que impedían o limitaban el avance económico, la movilidad social y la formación de un capital humano habilitado que se integrara en amplias franjas de población en la ruta del progreso ${ }^{3}$.

2 José Medina Echavarría arribó a México en 1939 y permaneció en nuestro país hasta 1946. Fundó, junto con Daniel Cosío Villegas, el Centro de Estudios Sociales en El Colegio de México (1943-1946) y fue coordinador de la Sección de Sociología en el Fondo de Cultura Económica (1939-1959). Después de su estancia en la Universidad de Puerto Rico, entre 1946 y 1952, se incorporó a la CEPAL en Santiago de Chile, donde permaneció hasta 1974, tres años antes de su deceso en esta ciudad. Una de las investigaciones más rigurosas y solventes sobre la vida y obra de Medina es la de Morales (2017).

3 Es importante recordar que después de la Segunda Guerra Mundial tuvo lugar en América Latina un amplio proceso de institucionalización y profesionalización de las ciencias sociales, con la finalidad de explicar las razones de los rezagos frente a la modernización en la región. De ahí la necesidad de generar nuevos conocimientos 
En este orden de ideas, el artículo se plantea como objetivo explicar un problema que marca la vigencia de las reflexiones de Medina: la centralidad de la teoría y conceptos ampliamente consolidados y compartidos, que fueran el punto de partida en el desarrollo de una sociología que él denominó "circunstanciada". Con este término se refería a un quehacer de observación e investigación profundamente vinculado con la experiencia de vida y fenómenos del entorno. Este ejercicio sociológico tenía como condición de posibilidad la reflexión conceptual, que para Medina implicaba no sólo un problema de enunciación de una realidad histórico-social determinada, sino la forma de dotar de significado y orientación a experiencias y problemas que eran nuevos y, a la vez, herederos de legados y tradiciones posibles de re-enunciar en el presente. Esta tensión entre la innovación conceptual y teórica y la indispensable traducción, edición y estudio de legados sociológicos de los clásicos, fue uno de los trazos dominantes en la trayectoria intelectual del sociólogo español. En este artículo nos enfocaremos en formular un panorama de sus reflexiones sobre la centralidad de la teoría en la delimitación de los objetos de estudio de la sociología ${ }^{4}$. En la primera parte del artículo analizaremos cómo se produjo la transición de Medina de la filosofía del derecho hacia la sociología, ante la clara limitación analítica y conceptual de la primera para explicar las profundas transformaciones que presentaba el panorama internacional, posterior a la primera posguerra del siglo XX. Apuntó además en sus reflexio-

sobre las condiciones socioeconómicas locales, que explicaran mejor las limitantes para el desarrollo. La creación de la Cepal, en 1948, la Asociación Internacional de Sociología, el Programa Mundial de Desarrollo de las Ciencias Sociales de la Unesco, o la Sección de Ciencias Sociales de la OEA, promovieron modelos profesionales para la formación de científicos sociales en escuelas de alto impacto en organismos multilaterales y gubernamentales. La recepción predominante de la sociología norteamericana, las corrientes cuantitativas y los modelos de las teorías de alcance intermedio se empalmaron con el interés de Medina para consolidar la reflexión sociológica, sus metodologías y lenguajes, en un espectro mucho más amplio y profundo de reflexión (Blanco, 2010; Brunner, 1999; Garretón, 1982).

4 Sobre la contribución de Medina como traductor y editor, puede consultarse Moya (2007 y 2015). 
nes a la urgencia de una revisión teórica y conceptual profunda en la sociología, que diera cuenta de fenómenos, actores y circunstancias hasta entonces inéditos, mostrando así la necesidad de recuperar los legados sociológicos del siglo XIX y complementarlos con innovación conceptual.

En la segunda parte del artículo explicaremos algunas de las dificultades que Medina identifica en la producción teórica y conceptual de la sociología, entre ellas, la tensión entre investigación empírica y conceptuación, los diferentes tipos de conceptos en la sociología, la influencia weberiana de los tipos ideales sociológicos e históricos, y la comprensión de la teoría como un lenguaje de segundo orden y construcción hipotética, con capacidad heurística. Veremos cómo, para Medina Echavarría, uno de los mayores retos que tenía la sociología era consolidar una serie de reflexiones teóricas, en tanto cuadro ordenado y sistemático de categorías y principios para interpretar ciertos aspectos de la realidad social (Medina Echavarría, 1980).

\section{De la crisis de la filosofía del derecho al pensamiento sociológico: raciovitalismo y reflexión conceptual}

En la trayectoria intelectual de Medina Echavarría, los planteamientos sobre la función orientadora de la teoría en la reflexión sociológica tuvieron como punto de partida obras muy tempranas, como La representación profesional en las asambleas legislativas, de 1930, y particularmente La situación presente de la filosofía jurídica, de 1935. En México consolidó este problema bajo una perspectiva metodológica mucho más acabada en obras seminales como Sociología, teoría y técnica, de 1941, y Responsabilidad de la inteligencia, de 1943. En ellas podemos ubicar justamente una veta de reflexión sobre la crisis de la circunstancia política española en la coyuntura europea, que era palpable también en los planteamientos vacíos de sentido y escasa capacidad explicativa de la filosofía del derecho de las primeras décadas del siglo XX. 
Medina transitó hacia la sociología como un movimiento orientado a lograr una comprensión profunda de los signos contradictorios del desarrollo cultural de Occidente.

El autor desarrolló una reflexión sobre el estado de la filosofía del derecho y mostró que todos los sistemas explicativos formulados hasta entonces fueron pensados con la pretensión de validez absoluta y universal, y en mayor o menor medida lograron convertirse en corrientes dominantes de una época o bien en ortodoxias muy definidas. Sin embargo, ya en los años treinta del siglo pasado, difícilmente podría hablarse de una dirección filosófica dominante, debido al claro influjo del historicismo. La gran contribución de este último, señaló Medina, había sido reconocer el producto de una humanidad conocedora de su larga historia en sociedades con un extenso pasado, que añadió a los planteamientos normativos las relaciones con el mundo histórico. Se logró así la historificación del pensamiento, lo que implicaba que toda idea e institución se colocaban en la perspectiva histórica, tratándose de determinar su génesis y evolución (Medina Echavarría, 1935a, p. 10).

Por otra parte, al analizar la situación concreta del hombre occidental, la crisis se refería a una situación histórica, que veía con escepticismo y de forma vacilante las construcciones espirituales y sociales que dominaron en esta época y que aún no encontraban acomodo en un nuevo orden. Eran años en los que Medina Echavarría transmite lo que Francois Hartog denominó "experiencia del tiempo desorientado", y en los que Paul Valéry, en 1933, definió como una experiencia de ruptura de la continuidad, que confería a todos y cada uno de los hombres la sensación de pertenecer a dos eras, en las que se trastocó aún más la brecha entre presente y futuro (Hartog, 2007, p. 22). La crisis total del mundo contemporáneo significó entonces la disolución de las normas del mundo burgués, se planteó la posibilidad de una cultura totalmente irreligiosa en sus fundamentos, tuvieron lugar profundas transformaciones del capitalismo - que socialmente, afirmó Medina, se manifestaban en la paulatina integración de 
las mujeres al mundo laboral, la rebeldía juvenil, la expansión del régimen de masas y el correspondiente ascenso de regímenes fascistas- (Medina Echavarría, 1935a, pp. 14-15).

Se presenciaba la crisis de una civilización y del hombre que derivó en el replanteamiento de las filosofías desde las cuales estos fenómenos inéditos podían ser explicados. Estos últimos podían significar cosas distintas dependiendo de una actitud pesimista, señaló el autor, lo que derivaba en un diagnóstico como la decadencia de Occidente, a la manera de Spengler, o una más serena ante el futuro, para resolver lo que Ortega y Gasset denominó "el tema de nuestro tiempo". Medina Echavarría se identificó claramente con la mirada orteguiana, sobre la necesidad de superar tanto el racionalismo como el relativismo, en favor de una perspectiva filosófica denominada "raciovitalismo", desde la cual Ortega había considerado la necesaria europeización de España, sumida en el marasmo y las consecuencias de la Restauración (Medina Echavarría, 1939, p. 21-22).

Medina Echavarría vio en esta nueva filosofía una oportunidad para resolver el problema sociológico de las relaciones del individuo con la comunidad, origen del dramatismo de la situación política que se vivía en aquellos días. Una de las causas atribuidas al problema radicaba en el quebranto del derecho como forma de vida y al desmoronamiento de las construcciones jurídicas erigidas por la historia moderna de Occidente. Lo anterior significaba, nada más ni nada menos, percibir que la vida había perdido su forma jurídica, lo cual se reflejaba en la frágil construcción del Estado de derecho, su apagamiento frente al uso de la fuerza y el impulso que cobraba la guerra. Los verdaderos problemas de la filosofía del derecho eran metodológicos y conceptuales, pues carecía de un bagaje que permitiera enunciar las nuevas experiencias que para entonces caracterizaban el corazón de Occidente. Se requería entonces del análisis sociológico para explicar si por aquellos años se enfrentaba una situación coyuntural, o bien si hechos sociales como el derecho tal y como se había conocido tendía a desaparecer: ¿seguiría siendo fuente de orientación de la acción social? 
¿Podría mediar, regular, ordenar el funcionamiento institucional? El planteamiento que figura como trasfondo de estas preguntas radicaba para Medina en el perfil anómico de las sociedades occidentales, en las que, según Durkheim, si bien existía la norma, ésta había dejado de funcionar como un elemento constitutivo de orientación de la acción social.

Sólo la perspectiva raciovitalista y el pensamiento sociológico circunstanciado se convirtieron en brújula, filosofía y horizonte futuro para un autor que vivió tiempos desorientados. En Medina Echavarría parecía cumplirse aquel principio existencialista que señalaba que finalmente vivir significaba vivir para pensar y pensar para vivir, dada nuestra condición de seres problemáticos, que se hacían (debían hacerse) responsables de sí mismos. Esta responsabilidad se traducía en un doble imperativo cultural y vital que a Medina le permitió incursionar en la sociología y desde ahí aportar su propia comprensión y sentido de la crisis, pues transitó de la experiencia vivida como un actor derrotado por el ascenso fascista en España y luego exiliado, hacia la observación y comprensión sociológica de la circunstancia no sólo personal sino internacional (Medina Echavarría, 1941b, p. 42).

En su interpretación, Medina consideró que la crisis consistía en una situación de época, caracterizada por la profunda transformación por la que atravesaban las formas estatales, la estructura social, los productos de la cultura, el espíritu y el hombre, como consecuencia del radical cambio que implicó el aniquilamiento de formas anteriores, sin que se hubiera podido formular en plenitud otras que las sustituyeran. Por esta razón, el concepto de "crisis" equivalía en este contexto a vacilación y angustia. Frente a estas experiencias, se acrecentaba el estudio e interés por la sociología, disciplina a la que se llegaba por dos caminos concluyentes. Por una parte, para Medina, la conciencia interrogativa del hombre podía dirigirse al estudio y conocimiento de la vida social que se le presentaba vacilante y en ruinas, con la finalidad de conocer sus procesos internos y las causas de tal estado de cosas, o bien el hombre podía volver la mirada sobre sí mismo, con la pretensión angustia- 
da de conocer su propio y profundo destino, dar en algún momento con su ser social y derivar su atención hacia lo que constituía el ser social de su propia vida (Medina Echavarría, 1940b y 1940c).

Es decir, o se llegaba a la sociología como producto de la reflexión directa sobre los hechos sociales de una época o por la vía indirecta de la reflexión filosófica del hombre que se pregunta por las relaciones entre individuo y sociedad, no solo en términos de los profundos dilemas existenciales que implican una experiencia de caos, como el propio autor lo refiere, sino también en los términos de una comprensión científica de la naturaleza de las causas, las fuerzas y los elementos que habían llevado a aquella situación. Lo anterior marcó el origen y perdurabilidad de la sociología como reflexión de una época crítica sobre sí misma, de una época vacilante en sus estructuras sociales, tal y como Freyer lo había señalado por esos años (Freyer, 1930; Medina Echavarría, 1940b, p. 12).

En el pensamiento de Medina Echavarría, la sociología, definida como consecuencia de esta capacidad de autorreflexión sobre la modernidad y su crisis, era finalmente una manera de ver el mundo, que en este caso se vio claramente influida por la filosofía raciovitalista de la que había abrevado. De ahí que el punto de partida para la definición del concepto y campo de la sociología tuviera este contenido a la par de un enfoque circunstanciado. Para Medina, los hechos sociales de los que se ocupaba la sociología eran formas de nuestra vida y su realidad era una realidad vital. De esta naturaleza se desprendía una característica esencial: la de que, como formas vitales, estaban sujetas a la transitoriedad, es decir, a ser historia y estar penetradas por el avance sucesivo de los distintos momentos del tiempo, ya que nuestra vida en esencia no era otra cosa que historia. De ahí que, para el autor, pasado, presente y futuro fueran los momentos irreversibles en que transcurría la vida y nada que perteneciera a ella podía escapar a ese transcurso (Medina Echavarría, 1939, pp. 20-22).

Por esta razón, que los fenómenos e instituciones sociales fueran formas de vida explicaba para el autor por qué la sociología 
había tenido como preocupación esencial la comprensión de la realidad social contemporánea. Sus formas de vida debían interesarnos en la medida en que estaban unidas a nuestro tiempo y en que representaban nuestra situación sociológica, es decir, una parte de nuestra circunstancia. Abiertos a la vida y como parte de la totalidad de aquélla, nos encontrábamos ante un conjunto de formas sociales de las que formábamos parte y ante otras que nos rodeaban, integrando así el contorno social del mundo en el que estábamos inmersos. Lo más importante para Medina es que en el futuro la continuidad o la variación de estas formas sociales iban a depender de nosotros mismos, es decir, la dimensión del porvenir estaba abierta, de ahí que para Medina el destino de estas formas estuviera unido al nuestro.

Como podemos observar, para nuestro autor la sociología estaba necesariamente constituida por una experiencia de la temporalidad histórica, y el cruce de los horizontes pasado y futuro en el presente. La dimensión del futuro era medular y omnipresente en la medida en que la reconstrucción material y espiritual en Europa y la de nuestras vidas, afirmaba, eran aún posibles. Con todo, la orientación seguía aquí siendo presente-futuro, con la carga de esperanza que ello suponía. La perspectiva sobre el futuro era en un sentido moderno, que orientó aquello que para el autor era necesario emprender en el presente: el conocimiento científico de los hechos sociales y su constelación histórico-social, la comprensión de las dimensiones estructurales y vitales de la crisis, la mirada filosófica sobre la experiencia, los retos de la sociología y su necesaria orientación racionalizadora ${ }^{5}$. De forma

5 Medina Echavarría enfatizó el impacto de las filosofías de la vida o de la existencia que enmarcaron su reflexión sociológica. Primero Nietzsche, con su primacía de lo impulsivo en el hombre y su apasionada protesta contra lo racional; Dilthey, Simmel y Bergson, que plantearon la filosofía de la vida, y otro grupo de autores, como Scheler, Jaspers, Heinemann, Heidegger y Ortega (Medina Echavarría, 1940, p. 15). La reflexión que integramos aquí sobre los horizontes temporales provienen del concepto de regímenes de historicidad de Hartog (2007) y de las reflexiones de Koselleck sobre la experiencia de la temporalidad histórica (1993) 
complementaria, esta definición del presente era la fuente de resignificación del pasado en el pensamiento sociológico. De él habría de abrevar en dos sentidos particulares: para problematizar sobre los temas del objeto y método, la teoría y la técnica, y el otro sentido sin el cual todo resultaría incomprensible: la historicidad del hombre y todo el conocimiento que generaba, incluida por supuesto la sociología.

Solo bajo este acomodo de planos temporales se hacía visible para Medina Echavarría el valor de la sociología también como orientación para la vida, en cuanto el conocimiento de la realidad en que nos encontrábamos significaba darse cuenta de su estructura general y de sus manifestaciones particulares. De ahí que el autor planteara como preguntas medulares de la sociología: ¿cuál es la constelación de fuerzas y formas sociales de nuestro tiempo? ¿Cuáles son las condiciones sociales de nuestra existencia? ¿Qué constituye el basamento histórico de nuestra realidad? Bajo este orden de ideas, Medina retomó la definición de Freyer quien, en su intento por dar respuesta a estas preguntas, consideró esta disciplina como "autoconciencia científica de un presente humano" (Medina Echavarría, 1940c, p. 145). Si la vida era, en sus elementos radicales, circunstancia y decisión, la sociología podía proveernos del conocimiento lo más riguroso posible de nuestra circunstancia social, y profundizar sobre los motivos de las decisiones, aunque jamás podría sustituir el hecho de la decisión. Esta vertiente reiterada en su pensamiento derivó en la concepción de la sociología como ciencia de la realidad vital, y también como ciencia social concreta, es decir, circunstanciada.

Este último planteamiento de Medina Echavarría puede ser mejor comprendido si reconsideramos la propia experiencia de la temporalidad que este autor nos comunicaba en su obra, al reflexionar acerca de la crisis tanto de la cultura occidental de medio siglo como de la suya ante el desarraigo del exilio. Para un sociólogo como Medina los valores del pasado no orientaban más a las sociedades modernas y el presente de la posguerra causaba estupor, se experimentaba aceleración del tiempo y movi- 
miento, y el futuro era, a pesar de todo, un horizonte abierto a la acción. De ahí derivó su preocupación por difundir en América Latina el estudio de las ciencias sociales y contribuir a su institucionalización en México, Puerto Rico y por supuesto durante su larga estancia en la CEPAL.

La necesaria condición circunstanciada de la sociología, así como la consolidación de los patrimonios teóricos de la sociología, llevaron a Medina a retomar de Mannheim la distinción entre teorías verticales y horizontales. Las primeras se caracterizaban por su perfil acumulativo de tradiciones intelectuales, abstractas, generales y de amplio alcance explicativo, válidas en entornos sociohistóricos diversos. Por su parte, las teorías horizontales se referían al esfuerzo adaptativo indispensable de toda reflexión teórica, que por ejemplo demandaron las reflexiones sobre la modernización en América Latina. Este esfuerzo debía contemplar los ritmos históricos de los grupos humanos, así como la propia experiencia de temporalidad a la que estaban sujetos. El planteamiento del autor sobre las teorías verticales y horizontales significó dejar el trazo de un problema que no está del todo resuelto en su obra: la tensión constante entre la indispensable elaboración teórica, en el sentido de los tipos ideales sociológicos weberianos, y la conformación de otras elaboraciones teóricas más acotadas, o circunstanciadas, pero no en el sentido de una teoría de alcance medio, a la manera de Merton, sino como tipos ideales de carácter histórico (Weber, 1984, pp. 159-165; Weber, 2014, pp. 238-245).

Con esta experiencia y reflexión acumuladas, Medina formuló su trabajo sobre los aspectos sociales del desarrollo, en calidad de teoría horizontal, es decir como sociología circunstanciada o concreta. Lo anterior consistió en abrevar de los legados conceptuales clásicos - por ejemplo, de la sociología económica weberiana-, y con ellos observar, analizar y delimitar algunas hipótesis sobre las tendencias y novedades que un fenómeno determinado presentaba. Este fue el caso de la insistencia de Medina para estudiar las racionalidades de los distintos actores sociales partícipes y objeto de las políticas de desarrollo locales, mostrando así 
un modelo explicativo alternativo frente al fracaso desarrollista (Medina Echavarría, 1969, pp. 65-67; Moya, 2013, pp. 350 y ss.).

\section{Las dificultades de la representación conceptual: las tensiones entre los legados y la innovación, la investigación empírica y la producción teórica}

Como resultado del diagnóstico de crisis de las sociedades occidentales de la época de entre guerras, Medina profundizó en el necesario vínculo entre las formas vitales y la elaboración conceptual, indispensable frente a la aparición de fenómenos inéditos, y otros cuya regularidad era necesario explicar. Para el sociólogo exiliado, la reflexión sociológica permitía la elevación de la experiencia cruda - de la pura percepción de los hechos y acontecimientos - a experiencia vivida y luego a la elaboración conceptual en el marco de la sociología. Lo anterior se desprende de la propia concepción de Medina sobre el papel de los intelectuales exiliados. Algunos de sus contemporáneos, como Gaos o Sánchez Vázquez, Eduardo Nicol, Eugenio Imaz o María Zambrano, dedicaron largas páginas a la reflexión sobre la experiencia del transtierro (Gaos), aterramiento (Sánchez) o el exilio como identidad (Zambrano) del exiliado; sin embargo, en el pensamiento de Medina el exilio era una condición de posibilidad para trascender la experiencia personal y convertirla en una parte de la reflexión y necesaria conceptuación sobre la crisis y el compromiso de los intelectuales (Medina Echavarría, 1943a y 1943b). Esta producción de sentido en la sociología era crucial para el avance y actualización de esta disciplina. Se conceptuaba cuando nos referíamos a fenómenos sociales reiterados en una dimensión diacrónica y que cobraban además una dimensión pública en la vida de las sociedades. En Medina se produjo un entrecruzamiento vital y analítico acerca del significado de la crisis de la modernidad temprana y su propia condición como intelectual exiliado. Éstas fueron las coordenadas bajo las que analizó la necesaria elaboración de la sociología como ciencia social concreta. 
Como parte de su transición hacia la reflexión sociológica, Medina planteó desde sus primeras publicaciones la centralidad de la reflexión teórica y conceptual, frente a fenómenos sociopolíticos y económicos inéditos, primero en Europa y posteriormente en América Latina ${ }^{6}$. Asimismo, mostró las limitaciones de ciertas categorías para explicar las profundas transformaciones que presentaba el panorama internacional de la primera posguerra, la Guerra Civil española, el curso de la Segunda Guerra Mundial y sus efectos. Fue a partir del Panorama de la sociología contemporánea que Medina consideró que la sociología como ciencia requería consolidar su legado conceptual y también innovarlo, de ahí el papel de la teoría para lograr una interpretación coherente y sistemática de los fenómenos estudiados ${ }^{7}$. Para el sociólogo español, la sociología requería de la construcción sistemática, es decir, de un fuerte componente teórico y conceptual que permitiera aprehender los elementos constantes de la experiencia social, a la par de posibilitar una sociología como ciencia concreta, pero no en el sentido de una ciencia aplicada: su carácter concreto, al igual que en toda ciencia social, era una consecuencia de la

6 En este artículo retomamos la distinción entre palabras y conceptos, a partir de la reflexión de Reinhart Koselleck. Señala que las palabras corresponden al contexto o situación a la que se alude, y sus significados pueden ser establecidos con exactitud mediante definiciones. Una palabra puede convertirse en concepto en el momento en que logra aglutinar la pluralidad de experiencias históricas y diversos estratos de significado, tanto teóricos como históricos. En este sentido, puede afirmarse que los conceptos son concentrados de numerosos contenidos significativos que se adhieren a la palabra. En la medida en que aglutinan capas de significado, están sujetos a ser interpretados. Desde la historia conceptual, que entrelaza historia social, experiencia de la temporalidad histórica y acumulación de experiencias significadas, las categorías son indicadores y factores de la experiencia (Koselleck, 2002, p. 253; Koselleck 2012, pp. 23-25, 31-35, 95).

7 Introducción a la sociología contemporánea fue el texto precursor del primer libro que José Medina Echavarría publicó en México en 1940, bajo el título de Panorama de la sociología contemporánea. En esa obra Medina reunió el resultado de su cátedra de Sociología, de la Universidad Central de Madrid, en 1934. Tuvo programada su publicación en la Revista de Derecho Privado, pero el estallido de la Guerra Civil española truncó el proyecto. En 2008, el Colegio de México reeditó Panorama de la sociología contemporánea, con un anexo documental de los textos originales de Medina que ya no integró a la edición mexicana de su obra en 1940. Ver estudio introductorio de esta edición (Moya y Morales, 2008). 
historicidad de su materia y la de aquellos que la cultivaban. Lo anterior exigía que nos aproximáramos a ella con la ayuda de soportes teóricos, decía Medina, con un mínimo de consistencia y continuidad (Medina Echavarría, 1940, 1941 y 1953).

Así, Medina desarrolló en el Panorama de la sociología contemporánea un largo apartado sobre sociología general en el que, a partir de una clasificación bastante aceptada en esos años entre teoría de las relaciones y teoría de las estructuras, delineó un marco conceptual básico de sociología muy parecido al planteamiento de Hans Freyer en La sociología ciencia de la realidad. En esa obra, publicada en 1930, Freyer planteó un problema teórico metodológico que Medina Echavarría desarrolló en numerosos artículos y libros: cómo construye la sociología sus categorías de análisis, es decir, de qué manera establece una retroalimentación entre la historia, como proveedora indispensable del recuento de la experiencia humana, y la pretensión sociológica de generalizar, formular hipótesis, problematizar y en especial construir sus categorías. Con posterioridad, nuestro autor amplió este horizonte de reflexión para analizar cómo la sociología construía su edificio teórico y la imprescindible relación que este último guardaba con la dimensión empírica.

En sus primeros años como sociólogo, Medina retomó los planteamientos de sociología del conocimiento — de Dewey, Znaniecki y Mannheim - para investigar acerca de la teoría en su calidad de construcción hipotética y la dimensión sistemática de la sociología, no en el sentido filosófico, a la manera de Ortega y Gasset, sino en el sentido científico de posibilitar la observación de procesos sociales que presentan cierta regularidad, construir

8 La reflexión de Medina sobre algunos conceptos sociológicos fundamentales tuvo como uno de sus ejes articuladores la transición de las organizaciones sociales tradicionales hacia la primera modernidad, de ahí la centralidad en sus textos de conceptos como "comunidad", "sociedad", "sociedad estamental" y "sociedad de clases". En los años treinta del siglo pasado, Medina Echavarría comparó las ideas de autores tan diversos como Tönnies, Weber, Freyer, Vierkendt, Oppenheimer, Wiese, entre otros. 
los datos y establecer explicaciones. En este orden de ideas profundizó en la relación entre principios generales y realidad social, la dimensión a priori de la teoría, o la reflexión sobre los tipos de teoría sociológica, y los diferentes niveles de abstracción de sus conceptos (Medina Echavarría, 1941a y 1943a).

Asimismo, la reflexión teórica de Medina pretendió dotar a la sociología de un sólido patrimonio conceptual que le permitiera reafirmarse como una ciencia social concreta. De ahí que para el sociólogo español resultara indispensable analizar las diferencias entre categorías de máxima impregnación histórica o bien de pertinencia espacio temporal muy acotada, y otras con un nivel mayor de generalización y abstracción, propios de una realidad social típico-ideal pura9. Con este fin escribió y reescribió una de sus obras más completas, comprensivas y sistemáticas: La sociología como ciencia social concreta, que reunió sus lecciones de sociología para la Universidad de Puerto Rico entre 1946 y 1952. Este material fue el punto de partida para una reflexión profunda y madura, y que requirió reescritura durante las siguientes dos décadas ${ }^{10}$.

Sin embargo, vale la pena preguntarse cómo fue construyendo Medina sus ideas sobre la teoría y los conceptos, una vez que incursionó en la sociología. En 1941, desarrolló en Sociología, teoría y técnica una profunda reflexión sobre los fundamentos epistemológicos de la conceptuación, tan necesaria en la sociología.

9 Para Medina la elaboración de conceptos abarcaba tres posibles niveles de generalización y abstracción, que obedecían a la combinación de tres factores: los diversos perfiles de los objetos de estudio, el alcance explicativo pretendido por el investigador y la presencia en menor o mayor grado de descripciones históricas o generalizaciones en el concepto. En este sentido, podía hablarse de conceptos generales cuya pretensión era contener o apresar fenómenos que se presentaban de manera reiterada en cualquier sociedad; los conceptos históricos relativos que tenían un contenido de coordenadas espacio-temporales más acotadas, con un alcance de generalidad menor, y finalmente los conceptos históricos individuales, que pretendían captar lo singular o lo que sólo se daba una vez y no se repetía, destacando su condición irrepetible (Medina Echavarría, 1980, pp. 17-18).

$10 \mathrm{Al}$ respecto, puede consultarse la recopilación de textos de Medina y la introducción que elaboró Jorge Graciarena al publicar La sociología como ciencia social concreta, en 1980. 
Su punto de partida fue una pregunta fundamental: ¿qué era la realidad social a la que hacía referencia Freyer al señalar a la sociología como la ciencia que se ocupaba de ella? Medina Echavarría respondía que toda nuestra realidad era el producto combinado de dos elementos: la acción práctica y la capacidad de representación simbólica. Al decir "nuestra realidad" el autor se refería a la condición específicamente humana de ésta, que tenía como trasfondo la sociedad y sus códigos culturales. El punto de partida para el conocimiento de la realidad social era nuestra participación en las experiencias de los demás, de ahí que nuestra realidad fuera una experiencia socializada. El lenguaje hacía posible esa participación, significaba elaboración y socialización de la realidad formada en la praxis. Para Medina Echavarría, comunicación y comunidad se exigían mutuamente y se enriquecían en su necesidad recíproca. La copresencia de los demás, el vínculo entre comunidad y comunicación era factible sólo mediante los sistemas de símbolos, es decir, el lenguaje, nuestra primera interpretación del mundo (Medina Echavarría, 1941a, pp. 82-83) ${ }^{11}$. Después el investigador realizaba una interpretación de segundo orden, a partir de los conceptos sociológicos, como observador del proceso de interacción social.

En Sociología teoría y técnica el autor escribió uno de sus planteamientos más importantes sobre la elaboración conceptual en la sociología, pues la ciencia no era allí sino una prolongación y refinamiento del lenguaje cotidiano, y el método científico un desarrollo consciente y controlado de los procedimientos que llevaron a formular interpretaciones solventes y válidas de la realidad ${ }^{12}$. Los símbolos en la ciencia (conceptos e hipótesis que

11 Para Medina Echavarría, el lenguaje proveía de esta capacidad interpretativa del mundo; también se producían desfases entre el símbolo y la experiencia referida, producto de la selección de los datos sensibles y de la modificación de la actividad. De ahí que los símbolos y los conceptos sufrieran desfases y vaciamientos, tanto en el lenguaje cotidiano como en el disciplinar (Medina Echavarría, 1941a, p. 82).

12 Entre los autores que Medina retomó en esta reflexión estaban Hans A. Lindemann, con Weltgeschichte und Welterkenntnis, C. W. Morris, con Foundations of the theory of signs, y Stuart Chase, con The tyranny of words. 
derivaban en teorías) aparecían como una construcción del científico que valían en la medida en que se mostraran eficaces, es decir que pudieran ser corroborados en una repetida experiencia posterior, a partir de la contrastación con nuevos datos. Su construcción había de mostrar las operaciones realizadas para llegar a él de tal forma que pudieran ser repetidas por cualquier otro que los requiriera. A estos conceptos los calificaba como "operativos", pues facilitaban la comunicación y la comprobación. Mediante este proceso, la ciencia perseguía una socialización consciente y rápida de la realidad estudiada y tomaba un carácter colectivo y de cooperación científica. El concepto así constituido no debía quedar aislado de la actividad práctica, siempre y cuando en la ciencia se recordara algo que en la vida ordinaria no se cuestionaba y simplemente transcurría: nuestro saber era siempre relativo, fragmentado y esquemático, en clara alusión a la referencia a valores de Rickert. De ahí que fuera imposible la existencia de una ciencia sin teoría, como cuadro esquemático que sólo describiera y situara los fenómenos estudiados.

La elaboración teórica siempre se formulaba con carácter hipotético, es decir, la realidad que comunicaba era relativa, aun cuando la experiencia actual la confirmara, quedaba abierta la posibilidad de que nuevas experiencias exigieran su modificación o sustitución (Medina Echavarría, 1941a, pp. 87-95). En otras palabras, Medina pensaba en las teorías y sus conceptos como medios con los cuales la ciencia registraba y explicaba los cambios y estructuras de repetición que se presentaban en una sociedad. Observó la importancia de la capacidad de enunciación que dichas categorías debían contener y los posibles desfases a las que estaban sujetas a lo largo del tiempo ${ }^{13}$.

13 Koselleck ha señalado que entre los conceptos y su significado puede haber desplazamientos de diverso tipo. Hay contextos en que los conceptos aparecen con un excedente de significado y "adelantados a su tiempo"; también los significados pueden quedar rebasados por los acontecimientos; finalmente, se puede generar una situación de correspondencia entre las circunstancias y fenómenos y las categorías que los enuncian (Koselleck, 2008, p. 190). 
Sin embargo, las ciencias sociales - y en particular la sociología- se encontraban distantes todavía de lograr la conformación de un lenguaje operativo y riguroso, si se comparaba con el desarrollo logrado por las ciencias naturales ${ }^{14}$. Había afirmado que lo dicho sobre la realidad social como producto de la praxis y el simbolismo podía verse ahora como el problema de la relación entre el concepto científico y el hecho empírico al que se refería. Ambos debían acoplarse de tal modo que fuera posible el paso continuo de uno a otro. Esta interrelación, visible y con importantes resultados en otras ciencias, aún estaba distante en la sociología y se traducía en la desvinculación entre teoría e investigación empírica. Para Medina, Herbert Blumer ilustraba bien el problema en la psicología social y el resto de las ciencias sociales: la conceptuación imprecisa yacía en el meollo mismo de las dificultades científicas y estimulaba la bifurcación de la teoría y la investigación empírica. Frente a la interacción fecunda lograda en las ciencias naturales, este problema persistía en la sociología, que dejaba expuesta la reflexión teórica y la investigación empírica a una impugnación legítima por su carácter especulativo, pues aparecía sin plan, carecía de un objeto definido y todavía se reducía a un conjunto de observaciones producto de la inducción.

Ante el problema de cerrar la brecha entre el desarrollo teórico y la investigación empírica que derivara en una mayor capacidad de representación conceptual, Medina reconoció que el modelo que se invocaba en la ciencia social provenía de la física contemporánea, que había dado lugar a la dirección operacionista. Según esta tendencia, el científico dejaba la huella de las operaciones realizadas en la construcción de su concepto, de tal forma que otro investigador pudiera repetirlas y comprobar la adecuación del concepto construido al hecho empírico que pre-

14 Sobre el debate en torno a la unificación de las ciencias y el problema de la construcción conceptual, presente en el positivismo lógico, el behaviorismo, la filosofía de la ciencia y la semántica de mediados del siglo XX, Medina citó a Dewey y su Lógica: teoría de la indagación y el libro de Lundberg titulado Foundations of Sociology. 
tendía apresar (Medina Echavarría, 1941a, pp. 81-101). En el contexto de esta discusión, nuestro autor reconoció la necesidad de aprovechar los procedimientos de construcción conceptual empleados con un éxito notorio en la física, pero existía el problema de determinar en qué medida era aplicable a la ciencia social el método propuesto por esta ciencia dura (Medina Echavarría, 1941a, p. 99).

Para Medina, Max Weber aportó importantes elementos para resolver esta tarea y uno de los ejemplos más ilustrativos al respecto fue la elaboración de rigurosas definiciones del primer capítulo de Economía y Sociedad, que estaban concebidas como conceptos amplios generales referidos a los componentes constantes de la vida social, válidos en cualquier contexto. Para el sociólogo español, era necesario reconocer que ciertos conceptos referidos a la conducta humana eran inaccesibles a la denominada "depuración operativa". En otras palabras, eran modelos puros de acción social racional o, dicho en un sentido weberiano, tipos ideales puros. La precisión de los conceptos sólo podía obtenerse de forma relativa, afinando las formas de observación adecuadas a los datos a que se referían otros conceptos con un alcance histórico y explicativo más acotado y particular. Estos últimos eran los tipos ideales históricos, también propuestos por el sociólogo alemán ${ }^{15}$.

Fue a partir de esta primera reflexión sobre las tensiones entre conceptos y construcción de datos, y el debate sobre la operacionalización en las ciencias duras, que Medina Echavarría planteó otras coordenadas para la discusión: abordó el tema de la construcción y modificación de la teoría, entendida no como la suma de conceptos y argumentos generalizadores, sino como un conjunto de hipótesis cuyo punto de partida era la resolución de una situación problemática planteada en la disciplina. Señaló que una de las condiciones fundamentales de la reflexión teórica con-

15 Sobre el problema de la construcción conceptual en la sociología de Max Weber y la herencia de Menger en su pensamiento, puede consultarse (Aguilar Villanueva, 1988, pp. 235-255; Moya y Olvera, 2003 y 2008). 
sistía en que era indispensable que la teoría no perdiera el contacto con su base de experiencia, es decir, con el problema inicial, y que siguiera relacionada con alguna hipótesis para la solución del mismo ${ }^{16}$. Para el sociólogo español, la construcción teórica requería de las mismas condiciones para toda ciencia señaladas por el filósofo instrumentalista John Dewey: el estatus de las concepciones teóricas como hipótesis, considerar su función directiva en el control de la observación y que se comprobaran y revisaran de continuo sobre la base de las consecuencias que producían en su aplicación. Medina señaló que este proceso difícilmente se cumplía en las ciencias sociales de aquellos años, pues algunas teorías habían nacido con pretensiones de verdades absolutas y otras, si bien derivaron de una experiencia, se creyeron relevadas de confirmar si ésta continuaba invariable ${ }^{17}$.

En este orden de ideas y algunos años después, Medina Echavarría profundizó acerca de la teoría como uno de los elementos indispensables para la constitución de la sociología como una ciencia que, como todas, requería de la existencia de una interpretación coherente y sistemática de los fenómenos estudiados. Frente a los partidarios de una sociología exclusivamente empírica, inclinados a encontrar sólo en los hechos el verdadero obje-

16 Es importante señalar que Medina retomó a Dewey para explicar cómo la responsabilidad de la ciencia radicaba en la resolución de problemas, en particular aquellos que aparecían en el marco de las interacciones sociales. En su obra Lógica: teoría de la indagación (1938) señaló que la función del pensamiento reflexivo era transformar una situación en la que se tenían experiencias caracterizadas por la duda, el conflicto, o experiencias perturbadoras, convirtiéndolas en una situación clara, coherente, ordenada y armoniosa. En otras palabras, la investigación consistía en convertir una situación indeterminada en otra determinada (Reale y Antiseri, 2001, pp. 453-454).

17 Para Medina, la reflexión teórica estaba sustentada en una reflexión de corte filosófico, en la que retomó a Ortega y Gasset. En Ensimismamiento y alteración advirtió la relación entre vida y reflexión: para el filósofo español, el hombre se sentía perdido, náufrago en las cosas: era la alteración. Después el hombre, con un gran esfuerzo, se retiraba a su intimidad para formarse ideas sobre las cosas y su posible dominación: el ensimismamiento. Finalmente, el hombre volvía a sumergirse en el mundo para actuar en él conforme a un plan preconcebido, esto era la praxis (Medina Echavarría, 1941b, pp. 40-46). 
to y fin de la actividad científica, nuestro autor enfatizó que los acontecimientos sociales eran sólo una ordenación llevada a cabo por el investigador a partir de los materiales y evidencias recopiladas, en el marco de una teoría. Su ordenación en estructuras o formas determinadas, su adición, no ofrecía por sí misma ningún conocimiento en estricto sentido. La definición y clasificación de los hechos y su interpretación finalmente tenían como punto de partida una teoría (Medina Echavarría, 1953, p. 203). Para el autor fue muy importante destacar que en realidad toda construcción científica sólo tenía un valor heurístico válido en la medida en que se corroborara su eficacia desde la perspectiva de los propósitos de conocimiento perseguidos.

En síntesis, Medina Echavarría adoptó la clasificación y definiciones de Mannheim para el estudio de la sociología de aquellos años, la cual podía dividirse en sistemática y estructural o analítica, que correspondían cada una a dos planos diferentes de análisis ${ }^{18}$. Este fue el fundamento de su propia clasificación de las teorías en verticales y horizontales, a las que se hizo referencia en el apartado anterior. La sociología en su vertiente sistemática tenía como propósito "conducir la variabilidad de los fenómenos sociales a aquellos elementos y conceptos básicos de un carácter más o menos axiomático que hacen posible la sociedad en gene$\mathrm{ral}^{\prime \prime}$, es decir, estaba en el terreno de elaboración de los tipos ideales sociológicos de Weber (Medina Echavarría, 1941a, p. 106). Era una teoría sobre los elementos relativamente permanentes del hecho social y se integraba a partir de lo que Medina denominó como "conceptos sociológicos generales".

Por su parte, la sociología analítica posibilitaba la construcción de una investigación concreta, y sentar las bases del análisis circunstancial, ya fuera del presente o del pasado. Al sociólogo le interesaba una determinada configuración histórica, comenzan-

18 Se refiere Medina a un artículo escrito por Mannheim que apareció en el libro The social sciences. Their relations in theory and in teaching, de 1936. 
do por aquella en la cual vivíamos. El sociólogo, afirmó Medina, penetraba en esa configuración histórica a partir de la construcción conceptual provista por la sociología sistemática o analítica. Uno de los resultados de esta vertiente de investigación teórica consistía en proveer a la sociología de estructuras conceptuales con un menor nivel de abstracción y generalidad, es decir, de lo que el propio autor denominó "conceptos históricos relativos" y "conceptos históricos individuales"19.

En su vertiente estructural, la sociología enfrentaba importantes problemas metodológicos, bien diagnosticados por Ginsberg en 1934 en Sociology, y por Mannheim en Man and Society, de $1940^{20}$. Medina Echavarría los clasificó en tres grandes rubros: el problema de la relación entre los conceptos y principios generales y la realidad concreta en su configuración particular e histórica; los procedimientos que nos permiten comprender la interdependencia de los factores que intervienen en un proceso, de tal forma que pudiera realizarse una imputación causal o hipótesis, y, finalmente, la cuestión de la relación entre teoría y praxis, o bien, la reflexión sobre cómo se desarrolla un pensamiento de situaciones adaptado a las circunstancias (Medina Echavarría, 1941a, p. 115). Para el autor, un componente fundamental de estas discusiones fueron las reflexiones sobre los principia-media, entendidas como formas de refracción que toman los principios generales al plegarse a la realidad. Con esta afirmación, Medina enfatizaba la reflexión de Mannheim sobre la función de los principia-media en el proceso de investigación. Afirmaba que no se trataba de la comprensión de una situación concreta a partir de la intuición inmediata de una estructura, sino de un análisis circunstancial,

19 Nos referimos a los planteamientos de Medina Echavarría en La sociología como ciencia social concreta. El autor también señaló que autores como Durkheim, Pareto, Oppenheimer, Weber, Tönnies, Freyer, Mannheim, Hobhouse, Ginsberg, entre otros, habían realizado importantes aportaciones en el terreno de la sociología estructural. 20 Medina se refiere a la obra de Mannheim Man and Society in an age of reconstruction: Studies in modern social structure. En cuanto a Morris Ginsberg, el título completo es Studies of Sociology, publicado en 1932. 
metódicamente realizado desde la teoría, que mostrara el alcance explicativo de ciertas categorías.

Hacia mediados del siglo XX, después de exponer sus principales preocupaciones relativas a la fundamentación teórica de la sociología, Medina Echavarría privilegió el análisis sobre el impacto de los procesos históricos en la reflexión teórico-conceptual. En este orden de ideas, uno de los argumentos más reiterados del autor consistió en señalar que, en el pasado inmediato, las distintas teorías de la ciencia social eran consideradas como sistemas de verdades absolutas que no requerían de comprobación continuada. Sin embargo, los acontecimientos derivados de las Guerras Mundiales, el ascenso fascista y los efectos de la Guerra Civil española, entre otros, mostraban la invalidez de esta postura. Los datos sobre los que se había integrado una teoría se alteraban, modificaban o destruían en el proceso histórico, de ahí que perdiera toda su validez o demandara su replanteamiento ${ }^{21}$. Sin embargo, esta dimensión empírica en el proceso de elaboración teórica partía de un cuadro ordenado y sistemático de categorías y principios, un sistema que permitía interpretar la realidad y actuar en ella con un mínimo de certeza (Alexander, 2000). Únicamente desde ahí era posible desarrollar la dimensión empírica de la sociología, cuyo punto de partida era el orden conceptual de la teoría, siempre atenta a la actualización y habilitada para proveer de sentido a la aparente multiplicidad inconexa de los datos.

En esos años de madurez, Medina Echavarría sostuvo que si la sociología, como toda la ciencia, lograba construir su propia teoría, debía organizar en un sistema coherente de conceptos la experiencia de observación y cuestionamiento de la realidad social. Era una disciplina que, apoyada en esa construcción teórica, trataba de comprender qué era la realidad social en un momento determinado del pasado o del presente. Afirmaba el autor, siguien-

21 En este sentido, Medina cuestionó el alcance explicativo de conceptos como el de "soberanía" o "Estado nación", en la segunda posguerra. 
do a Mannheim, que no se trataba de "aplicar" los conceptos generales (la sociología analítica, sistemática o de teorías verticales) a un contexto social determinado, sino de ver observar, ordenar, caracterizar e interpretar mediante las categorías, y determinar cómo éstas posibilitaban la comprensión y mostraban a su vez su alcance explicativo (Medina Echavarría, 1953, pp. 65-67).

\section{Conclusiones}

Actualizar el legado y figura de un clásico de la sociología hispanoamericana como Medina Echavarría cobra sentido a la luz de una serie de preguntas pertinentes para nosotros, los sucesores, ubicados en las coordenadas de una modernidad tardía, entre ellas: ¿cuáles son las experiencias sociales inéditas que están siendo enunciadas y a la vez moldeadas por nuevos conceptos? O bien, ¿tenemos un déficit de construcción conceptual y teórica, en el sentido horizontal que nos propone el sociólogo español? ¿Cómo hemos resignificado o re-interpretado fenómenos sociales a la luz de las teorías sociológicas de las que hemos sido receptores en América Latina? Estos ejes de problemas podrían cobrar una mayor densidad en el análisis si consideramos que los conceptos encierran capas de significado, experiencias de la temporalidad histórica (una tensión entre espacio de experiencia y horizonte de expectativas) y una comprensión de la circunstancia (local, regional, nacional o global) que contribuyan a la formación de un discurso sociológico latinoamericano. Finalmente, Medina nos hereda la idea seminal de la sociología como ciencia social concreta o circunstanciada, cuyo punto de partida es la formulación teórica sistemática y una enorme capacidad para transformar los datos de la experiencia social en conceptos con diversos grados de alcance explicativo y generalización pertinentes. Nos recuerda que uno de los compromisos de la sociología consiste en lograr una reflexión teórica que permita la historificación de las experiencias sociales y la comprensión circunstanciada del propio entorno. Esta era el punto de partida de la sociología como ciencia social concreta, es decir, una verdadera ciencia de una realidad vital. 


\section{Referencias}

Aguilar Villanueva, L. F. (1988). Weber: la idea de ciencia social. Tomos I y II. México: Miguel Ángel Porrúa.

Alexander, J. (2000). Moderno, anti, post y neo: cómo se ha intentado comprender en la teoría social el "nuevo mundo" de nuestro tiempo", en Sociología cultural. Formas de clasificación en las sociedades complejas (pp. 55-125). Madrid: Anthropos.

Blanco, A. (2010). "José Medina y el proyecto de una sociología científica" en D. Pereyra (comp.), El desarrollo de las ciencias sociales. Tradiciones, autores e instituciones en Argentina, Chile, México y Centroamérica (pp. 17-34). San José: FLACSO-Costa Rica.

Brunner, J. J. (1999). Los orígenes de la sociología profesional en Chile, en E. Devés, J. Pinedo y R. Sagredo (comps.), El pensamiento chileno en el siglo XX (pp. 65-80). México: Secretaría General de Gobierno, Instituto Panamericano de Geografía e Historia, Fondo de Cultura Económica.

Freyer, H. (1930). La sociología, ciencia de la realidad. Fundamentación lógica del sistema de la sociología. Buenos Aires: Editorial Losada.

Garretón, M. A. (1982). Las ciencias sociales en Chile. Situación, problemas y perspectivas. Santiago de Chile: FLACSO.

Hartog, F. (2007). Regímenes de historicidad. México: Universidad Iberoamericana.

Koselleck R. (1988). Linguistic change and history of events. Journal of Modern History, 61, 650-666.

Koselleck R. (1993). Futuro Pasado. Para una semántica de los tiempos históricos. Barcelona: Paidós.

Koselleck R. (2002). The practice of conceptual history. Timing history: spacing concepts. Standford: Standford University Press

Koselleck R. (2004). Historia. Madrid: Trotta.

Lira, A. (1983). "Las ciencias sociales y el destino del hombre: notas sobre la obra de José Medina Echavarría". Relaciones, IV (18), 66-80.

Medina Echavarría, J. (1930). La representación profesional en las Asambleas Legislativas. Anales de la Universidad de Valencia, VII (52-54), 201-291.

Medina Echavarría, J. (1935a). La situación presente de la filosofía jurídica. Madrid: Editorial Revista de Derecho Privado. 
Medina Echavarría, J. (1934-1935b). Introducción a la Sociología contemporánea. Archivo General de la Administración de Madrid, Caja 32-13534, Alcalá de Henares.

Medina Echavarría, J. (1939). ¿Es la sociología manifestación de una poca crítica? Revista Mexicana de Sociología, l(2), 17-39.

Medina Echavarría, J. (1940a). John Dewey y la libertad. El Trimestre Económico, México, 24, 613-624.

Medina Echavarría, J. (1940b). Sobre la investigación social en nuestros días. Revista Mexicana de Sociología, 2(4), 17-35.

Medina Echavarría, J. (1940c). La sociología como ciencia de la realidad. (Alfredo Poviña). Revista Mexicana de Sociología, 2(1), 142-148.

Medina Echavarría, J. (1941a). Sociología, teoría y técnica. México: El Colegio de México, Fondo de Cultura Económica.

Medina Echavarría, J. (1941b). Reconstrucción de la ciencia social. Revista Mexicana de Sociología, 3(4), 35-56.

Medina Echavarría, J. (1943a). Responsabilidad de la inteligencia. Estudios sobre nuestro tiempo. México: Fondo de Cultura Económica.

Medina Echavarría, J. (1943b). Prólogo al estudio de la guerra. Jornadas del Centro de Estudios Sociales 1. México: El Colegio de México.

Medina Echavarría, J. (1953). Presentaciones y planteos. Papeles de sociología. México: Instituto de Investigaciones Sociales, UNAM.

Medina Echavarría, J. (1969). Discurso sobre política y planeación. México: ILPES-Siglo XXI.

Medina Echavarría, J. (1980). La sociología como ciencia social concreta (Jorge Graciarena, comp.). Madrid: Ediciones de Cultura Hispánica.

Medina Echavarría, J. (2008 [1940]). Panorama de la sociología contemporánea. (Estudio Introductorio y Selección de inéditos, Laura Moya y Juan Jesús Morales Martín). México: El Colegio de México.

Morales Martín, J. J. (2017). José Medina Echavarría. Vida y Sociología. México: El Colegio de México.

Moya López, L. A. (2007). José Medina Echavarría y la Colección de Sociología del Fondo de Cultura Económica, 1939-1959. Estudios Sociológicos, 75, 765-804.

Moya López, L. A. (2013). José Medina Echavarría y la sociología como cien- 
cia social. México: Centro de Estudios Sociológicos-El Colegio de México.

Moya López, L. A. (2015). Los universos textuales de José Medina Echavarría en México: la colección de Sociología del Fondo de Cultura Económica y la Colección Jornadas, en A. Valero (ed. y coord.), Los empeños de una casa. Actores y redes en los inicios de El Colegio de México 1940-1950 (175-197). México: El Colegio de México.

Moya López, L.A. (2016). José Medina Echavarría: Una mirada sobre América Latina desde la sociología económica y la teoría (1952-1977). Tempo Social, V.28. No.3, 95-116.

Moya López, L. A. y Morales J. J. (2008). Estudio Introductorio, en J. Medina Echavarría, Panorama de la sociología contemporánea, $2^{a}$ edición (pp. 9-76). México: El Colegio de México.

Moya López, L.A. y Olvera, M. (2003). Carl Menger y Max Weber: encuentros y desencuetros en torno a la teoría y los tipos ideales. Sociológica 18 (53), 15-68.

Ortega y Gasset, J. (1983). El tema de nuestro tiempo, en J. Ortega y Gasset, Obras Completas, T. III. Madrid: Alianza Editorial.

Palti, E. (2001). Introducción, en R. Koselleck, Los estratos del tiempo. Estudios sobre la historia. Barcelona: Paidós.

Reale, G. y Antiseri D. (2001). Historia del pensamiento filosófico y científico, Vol 1-3. Barcelona: Herder.

Weber, M. (1984). La acción social. Ensayos metodológicos. Barcelona: Península.

Weber, M. (2014). Economía y Sociedad. Edición anotada y estudio introductorio de Francisco Gil Villegas. México, Fondo de Cultura Económica. 